\title{
CRUSTAL STRUCTURE AND SURFACE-WAVE DISPERSION*
}

\author{
By Maurice Ewing and Frank Press
}

\section{INTRODUCTION}

A RECENT seismic refraction profile in $2,800 \mathrm{fm}$. $\left(5.1 \mathrm{~km}\right.$.) at latitude $34^{\circ} 00^{\prime}$ $\mathrm{N}$, longitude $66^{\circ} 30^{\prime} \mathrm{W}$, in the Atlantic Ocean proved that basement rocks having a velocity of $7.58 \mathrm{~km} / \mathrm{sec}$. for compressional waves were covered by $1.37 \mathrm{~km}$. of sediment. We tentatively identified this velocity with either the $P_{n}$ velocities used in earthquake seismology for the ultrabasic layer immediately beneath the Mohorovičic discontinuity, or with the deepest subdivision of the intermediate layer, indicating the absence of the granitic and upper part of the intermediate layers. This velocity is higher than most of the values deduced for the uppermost suboceanic rocks from studies of the velocity and the dispersion of earthquake surface waves over oceanic paths. If this refraction measurement is representative of ocean-wide conditions, it is evidently in conflict with the crustal layering inferred from previous studies on surface waves. The present study indicates that the observed surface-wave dispersion is to be expected if proper account is taken of the influence of the water and sediment over an ocean bottom consisting of a very thick ultrabasic ${ }^{2}$ layer, as indicated by the seismic refraction measurements.

\section{Inferences from the Airy Phase}

In a recent study ${ }^{3}$ of the Bermuda records of some West Indian earthquakes, a prominent new phase was investigated, with the conclusion that rocks with velocity higher than granite extended practically up to the ocean floor in this area. This conclusion was based on a theory of the normal-mode propagation of elastic waves in an ocean of uniform depth with a homogeneous solid bottom. The theory treated the case of an impulsive point source of compressional waves situated beneath the bottom. The theoretical dispersion at large distances from the source could be obtained from the period equation

* Manuscript received for publication August 1, 1949.

The research reported in this document has been made possible through support and sponsorship extended by the Geophysical Research Directorate of the Cambridge Field Station, AMC, U. S. Air Force, under Contract W-28-099 ac-396. It is published for technical information only and does not represent recommendations or conclusions of the sponsoring agency.

${ }^{2}$ Maurice Ewing, J. L. Worzel, J. B. Hersey, Frank Press, and G. R. Hamilton, "Seismic Refraction Measurements in the Atlantic Ocean Basin, Part I," Bull. Seism. Soc. Am., 40: $233-242(1950)$

${ }^{2}$ As the rock beneath the Mohorovičic discontinuity has been referred to by various leading scientists as dunite, peridolite, olivine, olivine basalt, gabbro, and ultrabasic, we use the term ultrabasic and intend it to be noncommittal in a petrologic sense.

${ }^{3}$ Frank Press, Maurice Ewing, and Ivan Tolstoy, "The Airy Phase of Shallow-Focus Submarine Earthquakes," Bull. Seism. Soc. Am., 40: 111-148 (1950). 


$$
\begin{aligned}
& \tan \left(k_{n} H \sqrt{\left.c_{n}^{2} / v_{1}^{2}-1\right)}\right. \\
& \quad=\frac{\rho_{2}}{\rho_{1}} \frac{\beta_{2}^{4}}{c_{n}^{4}} \frac{\sqrt{c_{n}^{2} / v_{1}^{2}-1}}{\sqrt{1-c_{n}^{2} / \alpha_{2}^{2}}}\left[4 \sqrt{1-c_{n}^{2} / \alpha_{2}^{2}} \sqrt{1-c_{n}^{2} / \beta_{2}^{2}}-\left(2-c_{n}^{2} / \beta_{2}^{2}\right)^{2}\right] \cdots
\end{aligned}
$$

where $\alpha_{2}, \beta_{2}$, and $\rho_{2}$ are the compressional wave velocity, shear wave velocity, and density in the bottom, respectively, $v_{1}$ and $\rho_{1}$ are the compressional wave velocity and density in the water, $c$ is the phase velocity, $H$ the water depth, and $2 \pi / k$ the wave length measured along the horizontal. An equivalent equation was given by Stoneley. ${ }^{4}$ Since available information indicates that the velocity of sound in the bottom sediments of ocean basins is approximately 10 per cent greater than that for water, we will consider $H$ to be the combined thickness of water and sediment.

It can be seen that $k_{n} H$ is a multiple-valued function of phase velocity, each value belonging to a distinct mode of propagation denoted by the subscript $n$. Now in a dispersive medium in which an arbitrary initial disturbance occurs, the energy associated with each wave length is known to propagate with the group velocity given by the familiar formula:

$$
U=c+\left(k_{n} H\right) \frac{d c}{d\left(k_{n} H\right)} \cdots
$$

The period equation (1) was used to calculate numerically $k_{n} H$ as a function of $c / v_{1}$, and the group velocity was subsequently determined by numerical differentiation according to (2). The results of these computations for $c \geqq v_{1}$ in the first mode are shown in figure 1 , where $U / v_{1}$ is plotted as a function of the dimensionless parameter $\gamma=H / v_{1} T . T=2 \pi / c k$ is the period. The computations were carried out for the two cases $\rho_{2} / \rho_{1}=2.5, \alpha_{2}=\sqrt{3} \beta_{2}, \beta_{2}=2 V_{1}$, and $\rho_{2} / \rho_{1}=3.0, \alpha_{2}=\sqrt{3} \beta_{2}, \beta_{2}=3 V_{1}$, which represent in an approximate way the conditions for a granitic and ultrabasic bottom, respectively. We may easily compute $U / v_{1}$ for values of $\beta_{2}$ slightly different from those assumed in figure 1 in the range $\gamma \leqq .22$ since $U$ is approximately proportional to $\beta_{2}$ for any given value of $\gamma$ in this interval.

The sequence of arrivals at a point distant from the source can be described with the aid of the group velocity curves. The first arrivals consist of very long-period waves $(\gamma \sim 0)$ traveling with the speed of Rayleigh waves $.92 \beta_{2}$. Subsequent arrivals show a decrease in period, corresponding to increasing $\gamma$. At a time corresponding to propagation at the speed of sound in water, a short-period wave arrives, riding on the continuing longer-period waves. The two simultaneously arriving wave trains thereafter approach each other in

\footnotetext{
${ }^{4}$ Robert Stoneley, "The Effect of the Ocean on Rayleigh Waves," Mon. Not. Roy. Astron. Soc., Geophys. Suppl., 1: 349-356 (1926).
} 


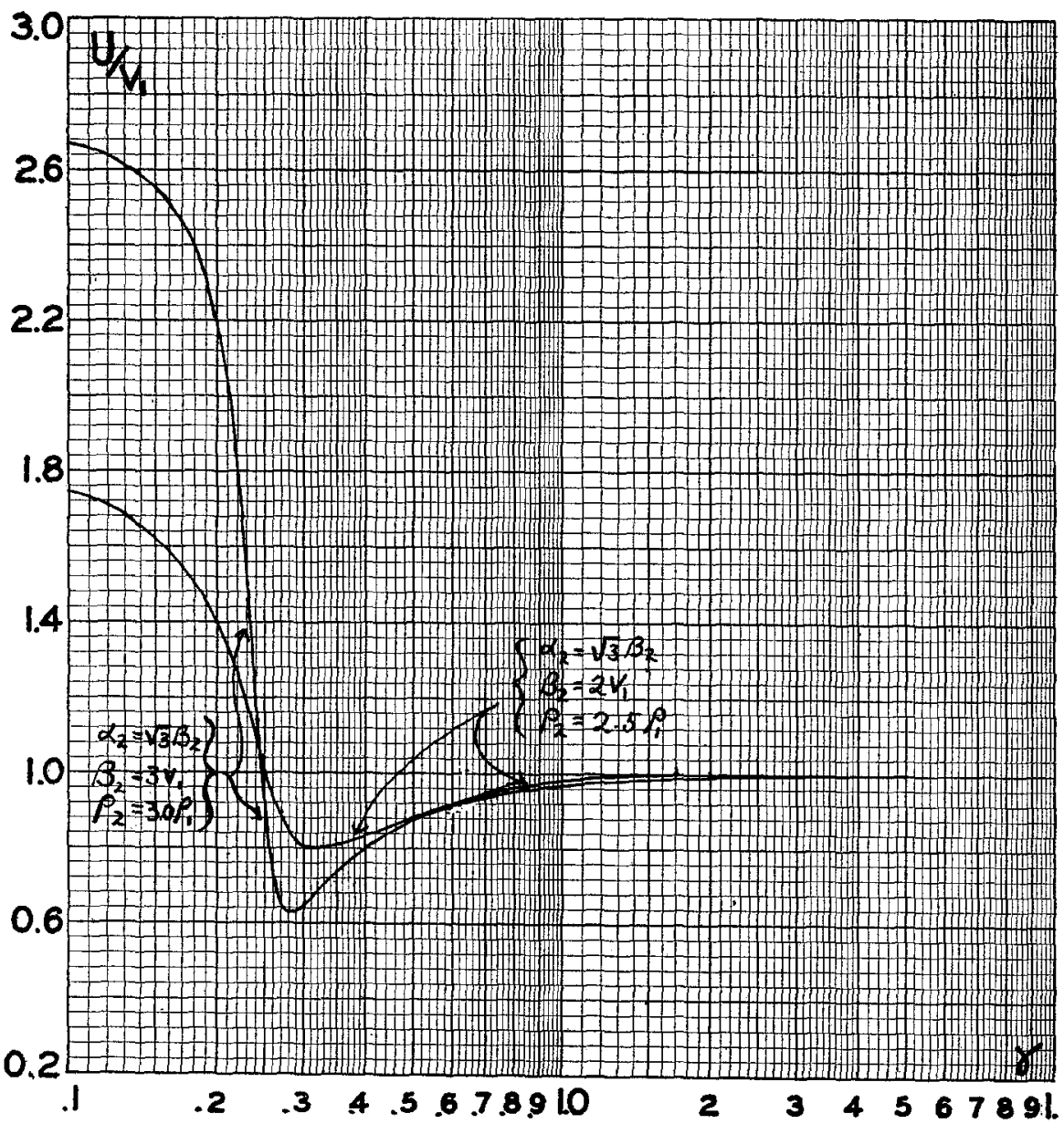

Fig. 1. Theoretical dispersion curves of suboceanic Rayleigh waves for granitic and basaltic bottoms.

period and finally merge into a train of waves of large amplitude, having a discrete period and traveling with the speed given by the minimum value of group velocity. The term Airy phase was introduced by Pekeris $^{5}$ to describe this train of waves.

The dispersion introduced by the layer of water over a thick layer of granite or ultrabasic rock can readily be calculated from the curves in figure 1 . It will be shown that the layer of water and sediment, neglected in previous studies, can account for the observed dispersion of suboceanic Rayleigh waves, if the ocean bottom is taken to be ultrabasic rock.

${ }^{5}$ C. L. Pekeris, "Theory of Propagation of Explosive Sounds in Shallow Water," in Propagation of Sound in the Ocean, Geol. Soc. Am., Mem. 27 (1948). 


\section{The Data of Wilson and BaykaL}

Wilson and Baykal ${ }^{6}$ studied the earthquake of November 25, 1941, at $37^{\circ} 0^{\prime} \mathrm{N}, 19^{\circ} 0^{\prime} \mathrm{W}$. They listed periods and velocities for the Rayleigh waves for six stations, some with mostly oceanic paths, others with mostly continental paths. They devised a method for separating out the continental and the oceanic dispersion effects on the assumption that the observed velocity of any period is a linear function of the percentage of its path which is oceanic or continental, and for obtaining "observed" dispersion curves for purely continental and for purely oceanic paths. They endeavored to explain the oceanic dispersion on the assumption of a crustal structure in which the ocean bed was a layer $26 \mathrm{~km}$. thick having a shear wave velocity of 4.0 $\mathrm{km} / \mathrm{sec}$. underlain by a thick layer with shear wave velocity $4.43 \mathrm{~km} / \mathrm{sec}$. The effect of the water was not considered.

The thickness $26 \mathrm{~km}$. was chosen to make the theoretical dispersion agree with that which was observed. The fit was good for the longer periods, but poor for the shorter ones. Wilson and Baykal reëxamined the seismograms and discovered that a pronounced change in character occurred for periods below about 18 sec. The change in character apparently consisted mostly of a marked decrease in amplitude and sharp deviation from the computed dispersion curve. The authors state that "at Weston the retrograde elliptical motions typical of Rayleigh waves continues beyond the change in character."

We have plotted the observed dispersion data for 100 per cent oceanic path as circles in figure 2. In this figure the theoretical dispersion curve is drawn for an ocean bottom with shear velocity $4.45 \mathrm{~km} / \mathrm{sec}$.

The agreement is excellent, taking the water-sediment thickness to be 5.25 $\mathrm{km}$. Approximately 75 per cent of the great circle path to Fordham lies in water deeper than 1,500 fm., with an average deep-water depth of $2,200 \mathrm{fm}$. or $4.0 \mathrm{~km}$. Thus a layer of sediments having an average thickness of $1.3 \mathrm{~km}$. is required in order for the observed and theoretical dispersion across deep water to agree. This is not unreasonable in view of the results of the refraction measurements described earlier.

Moreover, the Fordham data (chosen because the path comes nearest to an all-oceanic one) rejected by Wilson and Baykal and plotted as crosses in figure 2 appear as a normal continuation of the other data. The observed dispersion of Rayleigh waves under the Atlantic Ocean is thus accounted for by including the effect of the water and sediment, and assuming a homogeneous ocean bottom with compressional velocity $\alpha_{2}=\sqrt{3} \beta_{2}=7.7 \mathrm{~km} / \mathrm{sec}$, in good agreement with our refraction measurement. The dashed line in figure 2 is the theoretical curve given by Wilson and Baykal. For periods

" J. T. Wilson and Orhan Baykal, "Crustal Structure of the North Atlantic Basin as Determined from Rayleigh Wave Dispersion," Bull. Seism. Soc. Am., 38: 41-53 (1948). 
greater than 20 sec., it cannot be distinguished from our curve. For periods less than 18 sec., the two curves diverge.

The marked decrease in amplitude noted by Wilson and Baykal can be accounted for by the relatively steep slope of our group velocity curve for periods below $18 \mathrm{sec}$. The relative amplitude of the waves is known to be proportional to the inverse square root of the slope except near stationary values of the group velocity, where large amplitudes occur, but a closer

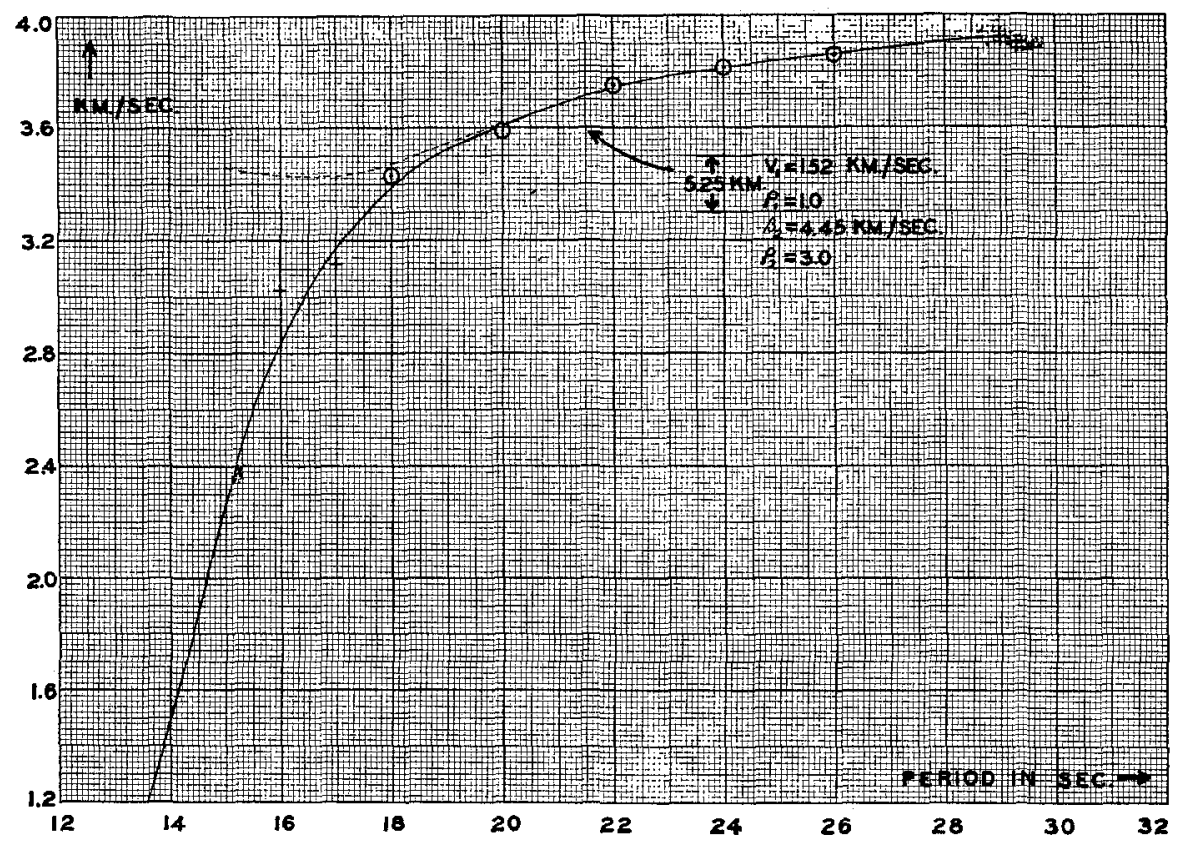

Fig. 2. Theoretical and observed dispersion of Rayleigh Waves in the Atlantic Ocean.

approximation is required. The curve of Wilson and Baykal (dashed line in fig. 2) has a stationary value of group velocity of about $3.43 \mathrm{~km} / \mathrm{sec}$. at a period of 16 to 17 sec., which would imply large amplitudes in the Rayleigh waves. He reports that the seismograms show low amplitudes and small change of period for large changes in travel time in this region, as illustrated by his tables and reproductions of the Weston and Fordham seismograms. As stated in the earlier section on the Airy phase, large-amplitude waves of period 9 to 10 sec. and velocities $1.06 \mathrm{~km} / \mathrm{sec}$. have been observed at Bermuda in fair agreement with the corresponding stationary value in our dispersion curve. 


\section{The Data of Bullen and Deliste}

Bullen $^{7}$ discussed the dispersion of Rayleigh waves recorded at Wellington from the earthquake of November 10, 1938, in the North Pacific at $55^{\circ} 6^{\prime} \mathrm{N}$, $157^{\circ} 7^{\prime} \mathrm{W}$. DeLisle ${ }^{8}$ included data from many additional stations for the same earthquake, several of which involved paths which may be considered to be entirely Pacific. 'These data were interpreted on the basis of Jeffreys' disper-

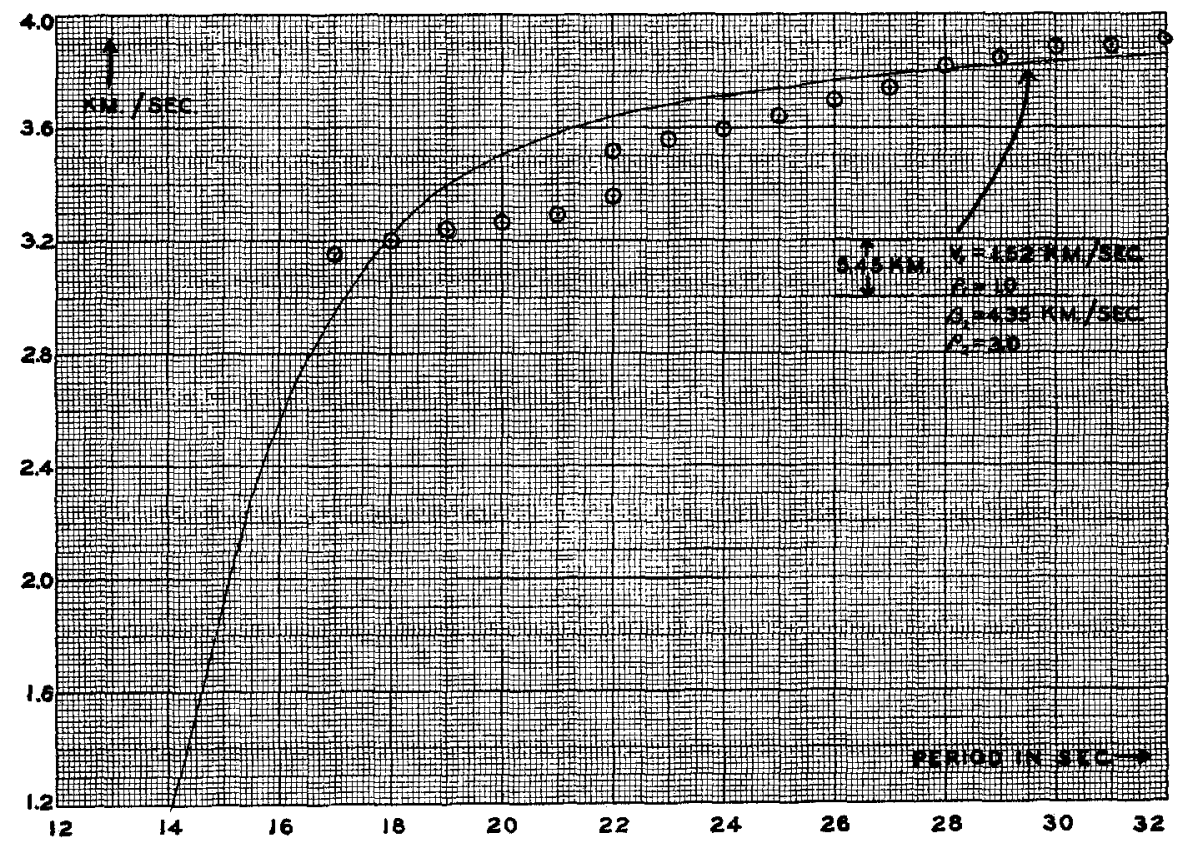

Fig. 3. Theoretical and observed dispersion (Wellington and Christ Church) of Rayleigh waves in the Pacific Ocean.

sion curves $^{9}$ (which take no account of the water) for Rayleigh waves. He took two solid layers with the ratio $\rho_{2} / \rho_{1}=5 / 4$ and $\beta_{1} / \beta_{2}=0.75$. This would include the case in which $S$ waves have a velocity of $3.3 \mathrm{~km} / \mathrm{sec}$. in the upper layer and $4.4 \mathrm{~km} / \mathrm{sec}$. in the lower. For each observed period they calculated the thickness of the upper layer which would correspond to the observed group velocity. The thickness ranged from about $6 \mathrm{~km}$. for 32 -sec. waves to about $20 \mathrm{~km}$. for 17 -sec. waves.

${ }^{7}$ K. E. Bullen, "On Rayleigh Waves across the Pacific Ocean, Mon. Not. Roy. Astron. Soc., Geophys. Suppl. 4:579-582 (1939).

8 J. F. DeLisle, "On Dispersion of Rayleigh Waves from the North Pacifie Earthquake of November 10, 1938," Bull. Seism. Soc. Am., 31: 303-307 (1941).

"Harold Jeffreys, "The Surface Waves of Earthquakes," Mon. Not. Roy. Astron. Soc., Geophys. Suppl. 3: 253-261 (1935). 
Observed dispersion obtained from the papers of Bullen and DeLisle are shown by the circles in figures $3-5$. The averaged data ${ }^{10}$ for Wellington and Christchurch presented in figure 3 is in fair agreement with the theoretical dispersion for a layer of water and sediments $5.45 \mathrm{~km}$. deep, overlying an ultrabasic bottom with shear wave velocity $4.35 \mathrm{~km} / \mathrm{sec}$. and density 3.0 . Approximately 80 per cent of the great circle path to Wellington was in deep water (depth greater than 1,700 fm.), with an average deep water depth of

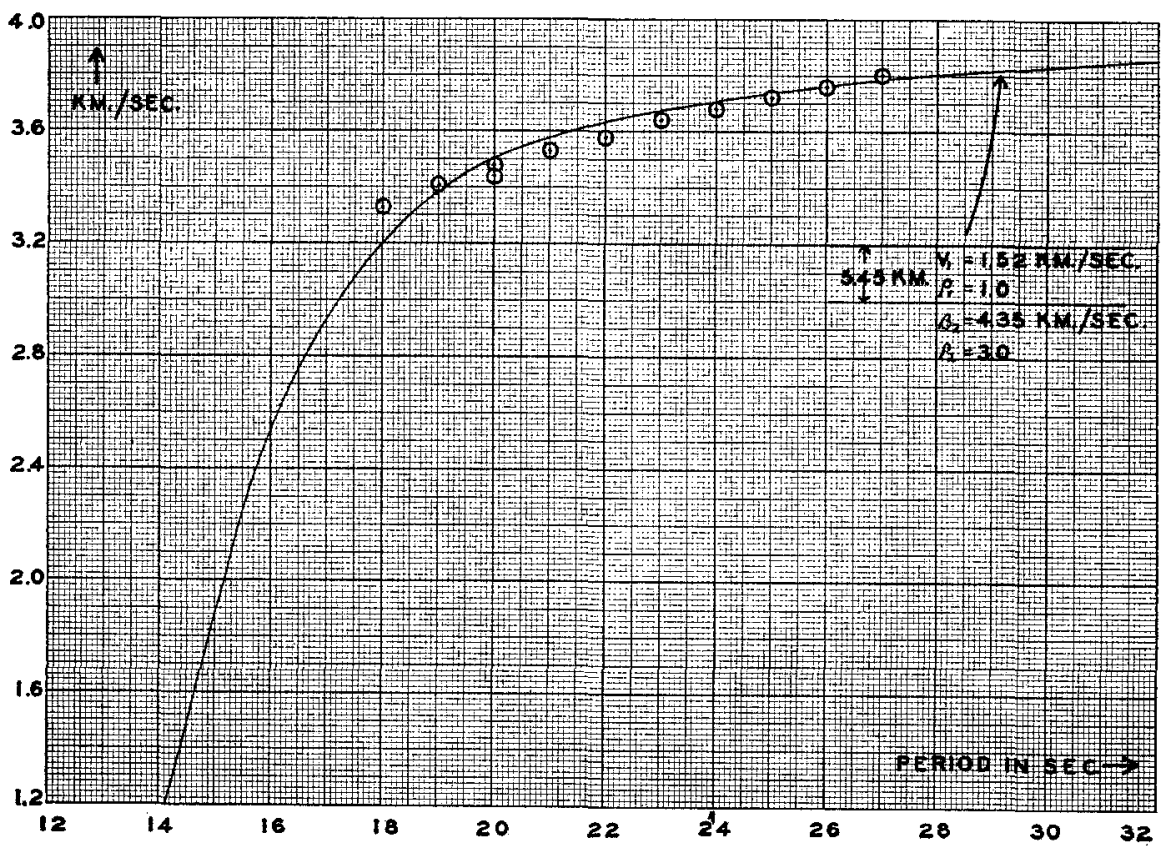

Fig. 4. Theoretical and observed dispersion (Apia) of Rayleigh waves in the Pacific Ocean.

$2,600 \mathrm{fm}$. or $4.8 \mathrm{~km}$. This is to be compared with the value $5.45 \mathrm{~km}$. obtained for the depth of water and sediments from the dispersion data, leaving a sedimentary thickness of approximately $0.7 \mathrm{~km}$.

The dispersion data for Apia shown in figure 4 agree quite well with the theoretical curve obtained for the same ocean-sediment depth and bottom velocity used in the previous paragraph. About 80 per cent of the great circle path to Apia was in water deeper than 2,000 fm., with an average deep-water depth of approximately $2,800 \mathrm{fm}$. or $5.1 \mathrm{~km}$.

The dispersion data averaged ${ }^{11}$ for the stations at Pasadena, Tinemaha, Santa Barbara, and Riverside for the same earthquake are shown in figure 5.

\footnotetext{
${ }^{10}$ In averaging dispersion data for several stations we have merely taken the average of the group velocities observed at each of the stations for each period.

11 See preceding footnote.
} 
The theoretical curve for a layer of water and sediments $4.78 \mathrm{~km}$. thick overlying an ultrabasic bottom with shear velocity $4.17 \mathrm{~km} / \mathrm{sec}$. and density 3.0 agrees reasonably well with the observed data. Approximately 60 per cent of the great circle path lies in water deeper than $1,700 \mathrm{fm}$., the average deepwater depth being $2,100 \mathrm{fm}$. or $3.8 \mathrm{~km}$.

The data of Bullen and DeLisle have not been corrected to allow for the part of the propagation paths which lies across shallow water and land. If we

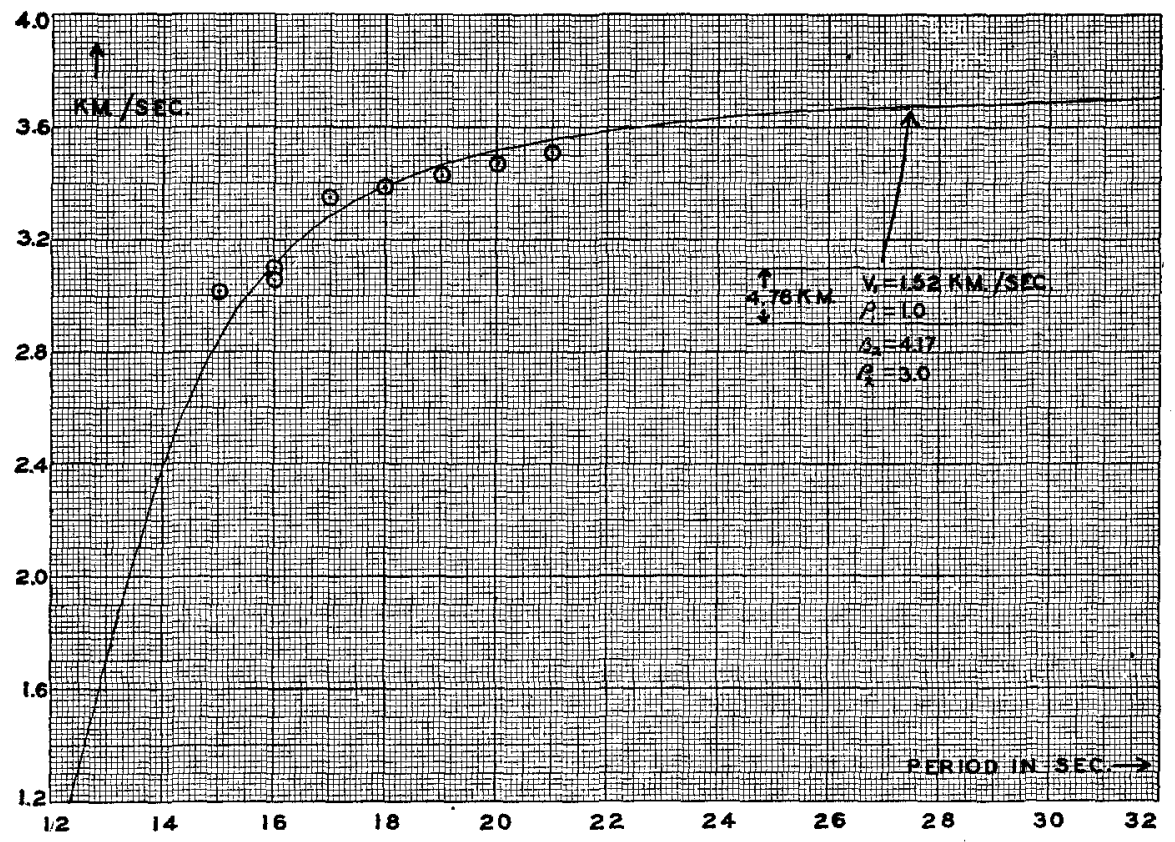

Fig. 5. Theoretical and observed (Pasadena, Santa Barbara, Riverside, and Tinemaha) dispersion of Rayleigh waves.

assume in the extreme case that the 20 per cent part of the path to the Wellington, Christchurch, and Apia stations which does not cross deep water is entirely continental, and derive "observed" oceanic dispersion using the method and data of Wilson and Baykal, the velocity $4.35 \mathrm{~km} / \mathrm{sec}$. of shear waves in the bottom derived from the dispersion data would be increased by approximately 3 per cent. Under the same assumptions for the part of the path (40 per cent) to the California stations which does not lie in deep water, the derived velocity $4.17 \mathrm{~km} / \mathrm{sec}$. of shear waves in the bottom would be increased by approximately 7 per cent.

The data for Manila are not presented since only a small part of the great circle path crosses deep water and the dispersion introduced by the water would be small or negligible. The character of the dispersion, however, is 
unlike that observed for continental paths; hence there might well be, here, a case in which the suboceanic crustal structure assumed by Bullen and DeLisle or Wilson and Baykal could be applied without considering the effect of the ocean.

\section{Love Waves}

The fact that the water cannot participate in the propagation of Love waves leads one to expect that the observed dispersion in this type of wave for oceanic paths would be far less than that for Rayleigh waves if the Rayleigh wave dispersion is due to the influence of the water and not to crustal layering. On the other hand, if the Rayleigh wave dispersion is due to crustal layering, the Love wave dispersion should be comparable to it in magnitude under the oceans as it is under the continents. Wilson, ${ }^{12}$ in his study of the Love waves of the South Atlantic earthquake of August 28, 1933, had available oceanic paths through the Atlantic, Pacific, and Indian oceans as well as mixed continental and oceanic paths. He found that the dispersion was much less along oceanic paths than along mixed paths, and that the dispersion for the three oceans was about the same. He attributed practically all the dispersion observed for mixed paths to the continental part. His observed group velocities for oceanic paths varied in a regular way from $4.3 \mathrm{~km} / \mathrm{sec}$. at 20 sec. to about 4.5 at $100 \mathrm{sec}$. This is in marked contrast to the variation of 3.3 $\mathrm{km} / \mathrm{sec}$. at $20 \mathrm{sec}$. to 4.2 at 100 sec. for continental paths.

An attempt will be made in a later paper to make a detailed analysis of the dispersion of Love waves over oceanic paths, but it seems clear that the small magnitude of this effect supports our interpretation of the Rayleigh wave dispersion.

\section{Discussion}

The velocity $4.45 \mathrm{~km} / \mathrm{sec}$. for shear waves, suggested for both the Atlantic and the Pacific Ocean basins by our study of the dispersion of Rayleigh waves, relates to the upper 50 to $100 \mathrm{~km}$. of the basement rocks. It involves the assumptions $\alpha=\sqrt{3} \beta$ and $\rho_{2}=3.0$, both of which are subject to changes of several per cent. But such changes would produce only a second-order effect upon the value of $\beta$; hence we consider that the value $4.45 \mathrm{~km} / \mathrm{sec}$. is unlikely to be changed appreciably.

For the corresponding velocity of compressional waves we obtain 7.71 $\mathrm{km} / \mathrm{sec}$. if we assume the ideal relation $\alpha=\sqrt{3} \beta$, but it seems far better to use the ratio $\alpha / \beta=7.94 / 4.46$ deduced from Jeffreys' table ${ }^{13}$ or $\alpha / \beta=8.0 / 4.5$, deduced from that of Gutenberg and Richter. ${ }^{14}$ On this basis our study of surface wave dispersion gives the mean velocity of compressional waves in the first 50 to $100 \mathrm{~km}$. beneath the ocean sediments as $7.95 \mathrm{~km} / \mathrm{sec}$.

12 J. T. Wilson, "The Love Waves of the South Atlantic Earthquakes of August 28, 1933," Bull. Seism. Soc. Am., 30: 273-301, (1940).

${ }^{13} \mathrm{H}$. Jeffreys, "The Times of P, S, and SKS, and Velocities of P and S," Mon. Not. Roy. Astron. Soc., Geophys. Supple., 4: 510-513 (1939).

${ }^{14}$ B. Gutenberg and C. F. Richter, Gerlands Beiträge, Vol. 54, p. 94 (1939). 
The velocity $7.58 \mathrm{~km} / \mathrm{sec}$. for compressional waves found in the seismic refraction measurement ${ }^{15}$ relates only to the upper one or two kilometers of rocks beneath the ocean sediment.

Our original interpretation of these results was that a single rock type extended for 50 to $100 \mathrm{~km}$. beneath the base of the oceanic sediments, that it was identical with the layer just under the Mohorovičic discontinuity under continents, and that the increase from 7.58 to $7.95 \mathrm{~km} / \mathrm{sec}$. was concordant with the rate of velocity increase with depth usually accepted for these rocks. The discussions of Byerly and Gutenberg have so strongly emphasized the trend of all recent results on $P_{n}$ toward values slightly greater than 8.0 $\mathrm{km} / \mathrm{sec}$. that we now admit the strong possibility that our $7.58 \mathrm{~km} / \mathrm{sec}$. represents the lowest part of the intermediate layer, and that our $7.95 \mathrm{~km} / \mathrm{sec}$. is an average representing a rather thin zone of the intermediate layer overlying " $\mathrm{P}_{\mathrm{n}}$ rock" in which the velocity of compressional waves is slightly more than $8.0 \mathrm{~km} / \mathrm{sec}$. Thin crustal layers alone could not produce the observed dispersion, but possibly could be detected by careful study of the seismograms, particularly in the region of the shorter-period Rayleigh waves.

\section{SUMMARY}

The observed dispersion of Rayleigh waves across the Atlantic and Pacific oceans can be accounted for by considering the propagation of such waves through a system consisting of water and unconsolidated sediments overlying a thick layer of ultrabasic rock. This contrasts with all former treatments, which have considered the effect of the water layer to be negligible. The depth of the water-sediment layer and the speed of shear waves in the underlying ultrabasic layer are obtained for several paths across the Atlantic and Pacific oceans. The results for the Atlantic are in good agreement with the data obtained in a recent seismic refraction measurement made 120 miles northwest of Bermuda, and offer strong evidence that the result of this single refraction measurement will be found to be typical of the entire ocean. No significant difference in the nature of the suboceanic basement of the Atlantic and Pacific has been found, since the velocity of shear waves in the uppermost 50 to $100 \mathrm{~km}$. was calculated to be $4.45 \mathrm{~km} / \mathrm{sec}$. for both oceans. Previously reported differences in Atlantic and Pacific velocities for Rayleigh waves of some selected period are now believed to be due primarily to differences in the depth of water plus sediment in the two oceans.

Lamont Geologtcal Observatory

(Columbra UNIVERsity)

Contribution No. 9.

\footnotetext{
${ }^{15}$ Maurice Ewing, et al., op. cit.
} 